\title{
CONTRIBUTION TO RESEARCH OF SPOILER AND DOME DEFLECTOR TVC SYSTEMS IN ROCKET PROPULSION
}

\author{
Nikola Davidović, Predrag Miloš, Branislav Jojić, Marko Miloš
}

Original scientific paper Physical model of spoiler and dome deflector thrust vector control (TVC) system was established considering previous and current research observations. According to logic of physical model an engineering mathematical model is derived. Model algorithm and results were analysed and explained. Finally, model data were confirmed with real motor tests.

Keywords: dome deflector; nozzle; spoiler; thrust vector control

Prilog istraživanju spojlera i kupole deflektora sustava vektora potiska u porivu rakete

Izvorni znanstveni članak Ustrojen je fizički model spojlera i kupolastog deflektora u sustavu upravljanja vektorom potiska (UVP) razmatrajući zaključke prethodnih i sadašnjih ispitivanja. Prema logici fizičkog modela razvijen je matematički model. Algoritam modela i rezultati su analizirani i objašnjeni. Konačno, rezultati modela su potvrđeni testovima realnog motora.

Ključne reči: kupolasti deflektor; mlaznik; spojler; upravljanje vektorom potiska

\section{Introduction}

Physical model of spoiler and dome deflector thrust vector control (TVC) system was established considering previous and current research observations. The main idea was to have mathematical model which is able to predict performance of TVC with engineering accuracy.

There are many different TVC system types, and all can be divided into two different classes:

- TVC systems with fixed nozzle

- $\quad$ TVC systems with movable nozzles.

The first class includes systems with simpler nozzle design, but with external or internal devices, which would produce additional nozzle losses, while the second class includes systems with much more complicated nozzle designs, requiring special technologies, but essentially free of any additional losses [13].

\section{Fixed nozzle TVC systems}

Fixed nozzle systems, as the name states, refer to nozzles that are solid mounted in the frame of the vehicle. The flow inside the nozzle is then changed in order to move the thrust vector. These were some of the first systems of thrust vector control developed in the Polaris and Minuteman rockets, as well as in many small rocket motors for tactical use. The classification of fixed nozzle systems falls into these categories:

- Fluidic systems

- Mechanical systems.

Fluidic systems are based on flow modification by the injection of different fluids into supersonic part of the nozzle. Injected stream generates oblique shock wave in front of injection point and separation of the flow just after the injection point. In separation-flow, the zone pressure is increased and so it generates the side force.
Liquid injection presents any addition of a fluid that changes the characteristics of the combustion. By changing the combustion on one side of the nozzle the thrust vector can be changed. The method of injection, as well as the fluid that is injected, are both topics of much debate and research. One of the biggest decisions when considering this method of thrust vectoring is the liquid that will be used. The two main divisions are whether the liquid will inhibit the combustion or contribute to combustion. Combustion inhibitors will tend to cool one side of the nozzle while combustion contributors will add fuel or other additives to increase thrust on one side of the nozzle. Advantages of this method of thrust vectoring are that it has fast response capability and adds to thrust by adding mass to the fluid stream. The disadvantages of these systems are that they are heavy in weight and the degree to which valve opens is not linearly related to the rate of change of the thrust vector.

Gas injection is very similar to liquid injection. The difference is that instead of new gas being added to the fluid stream combustion gasses are re-routed from behind the nozzle into the diverging section changing the flow through the nozzle itself. The advantages of this method are that additional fluids do not need to be stored onboard and so the system overall is lighter in weight. The downside to this method, however, is that the hot combustion gasses have to be routed through valves. In stationary tests, the valves could never be made reliable enough to consider further testing. Gas injection system has slightly better performance than liquid injection.

Mechanical systems are based on different mechanical obstacles, which are used to modify flow around obstacle and/or in the nozzle and so pressure distribution. Several mechanical TVC systems have been developed so far:

- Jet vane

- Internal maneuvering vanes

- Jetavator

- Axial jet deflector 
- $\quad$ Spoiler (jet tab)

- Domed deflector

- Segmented dome deflector.

The jet vane deflector is characterized by any fin or plate that is directly placed in the exiting flow of the nozzle. It is essentially an aerodynamic device, which works in a similar way as control fin; just it is not in free stream of the atmosphere air, but in the free stream of combustion product exiting from the nozzle. As the plate or fin moves, it causes the flow, exiting the nozzle, to deflect from the centreline of the rocket, producing normal force on the fin surface. Advantages of these systems are that the forces on actuators are low and thus they can be capable of quick response times.

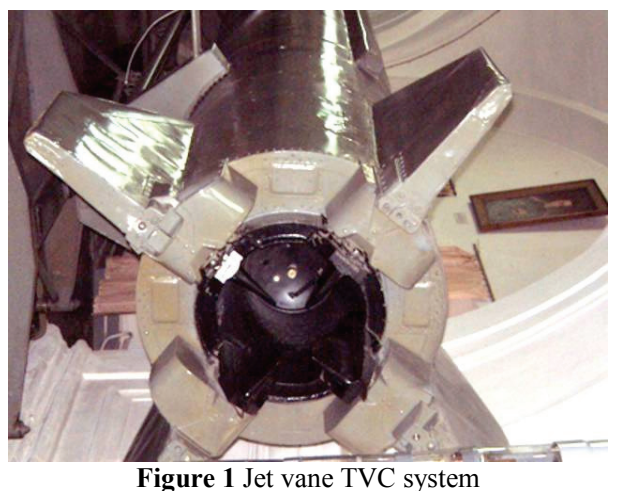

Since the blades are directly in the exhaust, this causes the designer to make one of three choices, the propellant can burn relatively cool, the propellant can burn for a relatively short period, or the vanes can be made of exotic heat resistant material. The other problem with this method is that a large deflection of the vane must be made in order to cause a change in the thrust vector. The large deflection and the inherent drag of fluid on the vanes reduce thrust. For difference to all other TVC systems, jet-vane produces additional losses even in zero-deflection position. It is the oldest TVC system, applied in many old-generation missiles, starting with German V-2 missile in the WWII.

Vanes are placed along the inside wall of the rocket nozzle. Being in the direct path of the hot thrust gases, the vanes are maneuvered by actuators to direct the thrust in order to better guide a rocket projectile. This type of system is common on surface-to-air missiles.

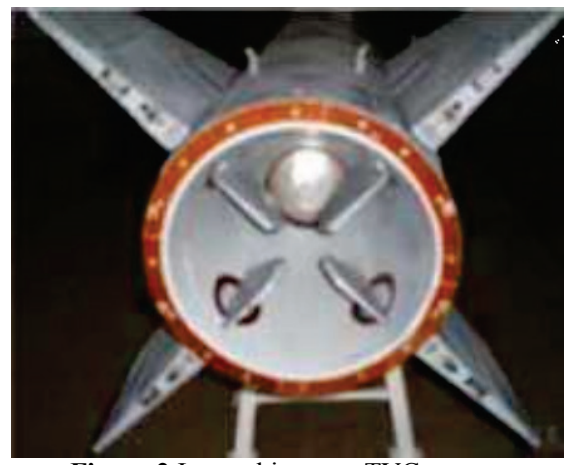

Figure 2 Internal jet vane TVC system

The jetavator is a similar concept to the jet vane. The difference is that instead of the vanes being in the nozzle flow, they are positioned around the perimeter of the nozzle and are parallel to the flow. This system has similar heat restrictions to the jet vane. Advantages include that the deflection of the jetavator is linearly related to the deflection of the thrust vector. The downsides of this design, besides the heat considerations mentioned in the jet vane section, are that the system can be heavy and that the jetavator restricts the exit diameter. Notable applications are F-16 and the Polaris A-1 missile.

Axial jet deflector is similar to jet vane in the fact that it does not modify internal flow in the nozzle. It is using pressure distribution around the deflector surface because of underexpanded nozzle. It has lower losses, but also lower maximum thrust-vector deflection than all other mechanical systems.

The spoiler (jet tab) system is characterized by a plate at the end of the nozzle that can be rotated into and out of the nozzle, thus disrupting the flow. Initial advantages that the thrust deflection is proportional to the area of the tab that is exposed to the flow make controlling the system relatively easy. The downside of this system is that when the tab is in the fluid stream the flow stalls on the tab. The stalled flow causes lots of erosion on the inside of the nozzle, but also additional losses.

Dome deflector is similar in working principle as jet tab, but its geometry is 3-dimensional. Because of that, not only nozzle walls, but also dome itself gives side force, so its performance is essentially better than the spoiler system. It was applied in many Russian tactical and long-range missiles.

Segmented dome deflector is similar to dome deflector, but it uses only one segment of the dome. It enables the usage of two segmented deflectors, thus giving possibility for controlling the missile around both perpendicular axes.

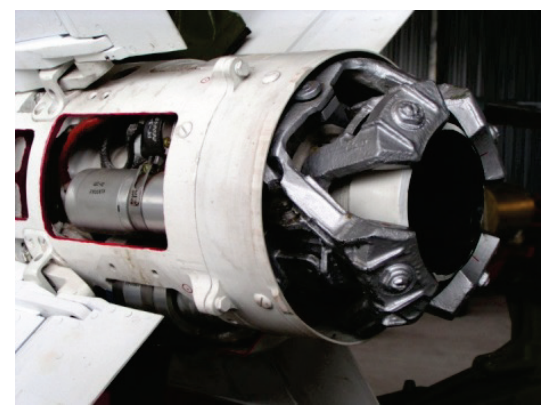

Figure 3 Segmented dome deflector at solid rocket motor nozzle (R73 air to air rocket)

Jet tab and dome deflector were selected to be the objects of the research for their simplicity, abundance of previous tests and data, as well as the fact that is proportional to the blocked area.

\section{Mathematical model of disturbed flow in the nozzle with spoiler}

Initially we accepted assumptions of previous investigations $[2,10,11]$ that the flow is practically identical in the case of spoiler and dome deflector. When an obstacle is present in the nozzle's exit area, the flow will turn its direction, which will cause a change in thrust vector. Change in direction is realized through the flow which can be described as the following [1, 4]: in 
divergent part of the nozzle, at distance $L_{\mathrm{s}}$ from the exit cross section, an oblique shock wave occurs (1). Boundary layer is becoming thicker with lambda shape (5) before separation point causing compressible (4) and expansion shock waves (3). In the disturbed zone, one recirculation zone exists, which is forming a so-called liquid wedge (6) [2]. In front of (before) the obstacle, a normal shock wave is formed (9). At point (7) normal shock wave is interacting with wave generated by the flow structure, after separation point, thus allowing for the mass interchange between zones. Flow interchange with recirculation zone is established through the mixture layer with main stream (2) and with mass losses through the nozzle-obstacle gap. At the top of the obstacle, the flow is accelerating through the expansion waves (8) as in Fig. 6.

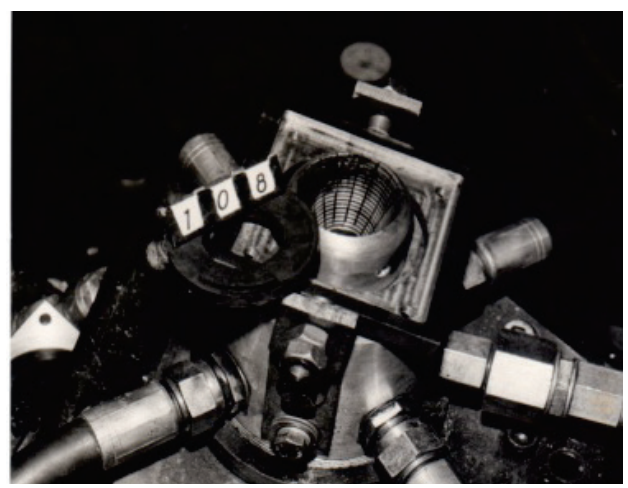

Figure 4 Model for flow visualization at Jet Propulsion Laboratory of the Faculty of Mechanical Engineering University of Belgrade [1]

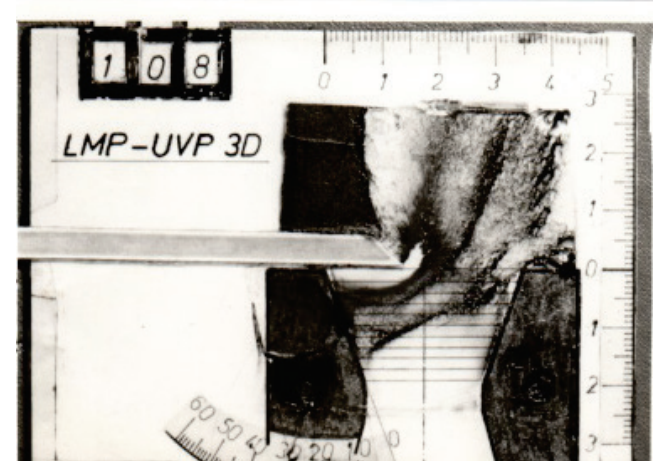

Figure 5 Flow visualization at Jet Propulsion Laboratory of the Faculty of Mechanical Engineering University of Belgrade, $A_{\mathrm{z}}=30 \%$ [1]

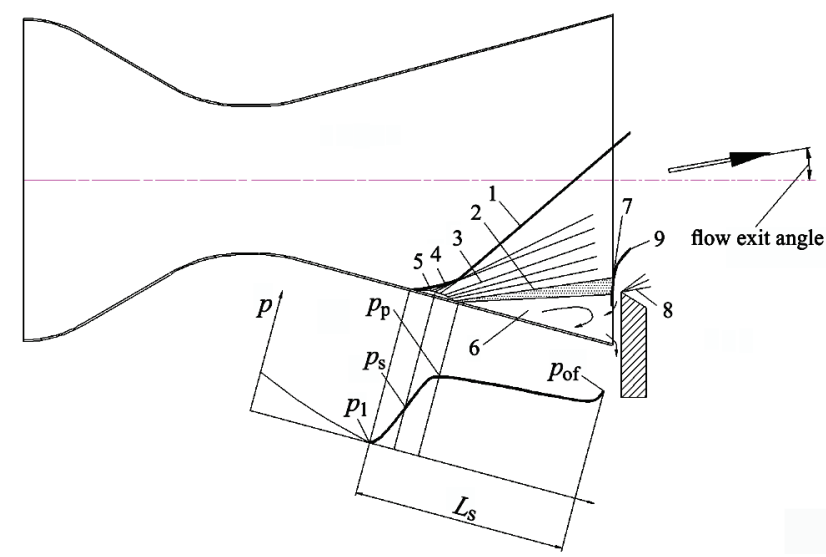

Figure 6 Scheme of physical model [1]

In order to calculate forces, it is important to know the pressure distribution along disturbed zone and obstacle. It can, logically, be concluded that flow (and consequently pressure distribution) depends on the following parameters (which were varied in tests):

- $\quad$ Relative blocked area of exit nozzle $A_{\mathrm{z}}=A_{\mathrm{b}} / A_{\mathrm{e}}$

- Relative gap between an obstacle and exit nozzle cross section $\delta=\delta_{\mathrm{a}} / D_{\mathrm{e}}$

- Angle between an obstacle and nozzle $\beta$

- Type of obstacle (spoiler, dome deflector).

Three types of tests were performed [1]:

- $\quad$ wind tunnel tests with measuring pressure distribution and flow visualization, Figs. 7, 8, 9 and 10

- $\quad$ laboratory tests with flow visualization, Figs. 4 and 5

- tests with air and rocket propellant gases with measurement of force.

The main difference from flat plate tests is that Mach number is not constant along the main oblique shock wave causing a curved shape. Another difference, when testing real solid rocket motor boundary layer is not isothermal. These important facts were taken into account for modelling.

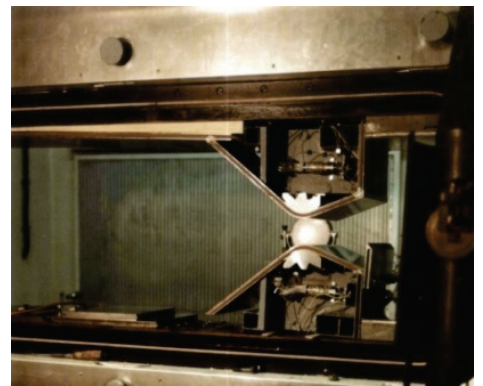

Figure 7 Model for wind tunnel tests [1]

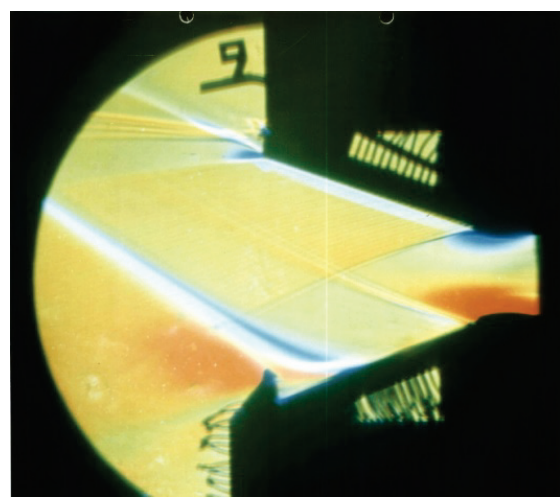

Figure 8 Schlieren photo from wind tunnel tests for $\beta=70^{\circ}, \delta=0$ and $A_{\mathrm{z}}=10 \%[5]$

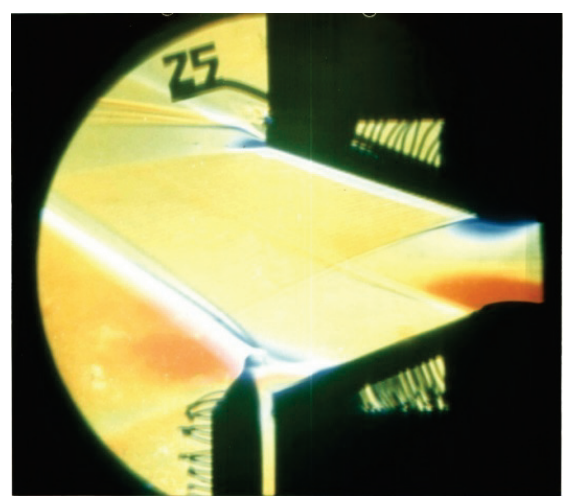

Figure 9 Schlieren photo from wind tunnel tests for $\beta=70^{\circ}, \delta=1 \%$ and $A_{\mathrm{z}}=10 \%$ [5] 


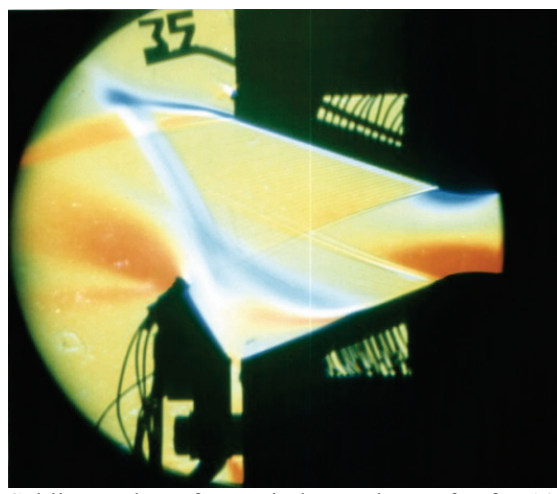

Figure 10 Schlieren photo from wind tunnel tests for $\beta=100^{\circ}, \delta=1 \%$ and $A_{\mathrm{z}}=30 \%$ [5]

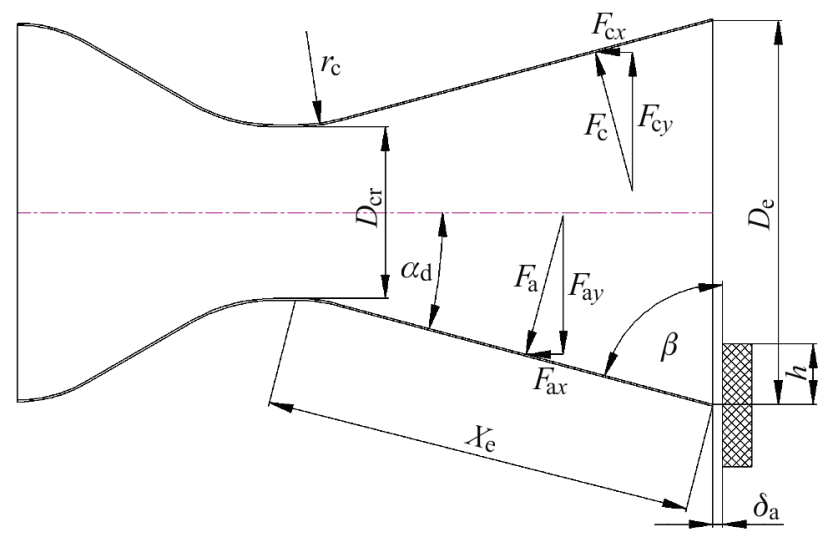

Figure 11 Model designations in mathematical model

Through the analysis of the results from all performed tests, the most suited engineering method for calculation of TVC performances was recognized. Considering the facts that the tests were performed on $2 \mathrm{D}$ or $3 \mathrm{D}$ nozzles, with spoiler and dome deflector, with hot gas or air, with measuring pressure distribution or measuring force, the following method is being proposed, according to Fig. 10 . The real 3D nozzle should be transformed to the equivalent $2 \mathrm{D}$ nozzle by:

$$
\begin{aligned}
& D_{\mathrm{cr}}(2 D)=\sqrt{\frac{\pi}{4}} \cdot D_{\mathrm{cr}}(3 D), \\
& \frac{A_{\mathrm{e}}}{A_{\mathrm{cr}}}(2 D)=\frac{A_{\mathrm{e}}}{A_{\mathrm{cr}}}(3 D), \\
& \alpha_{\mathrm{d}}(2 D)=\alpha_{\mathrm{d}}(3 D), \\
& r_{\mathrm{c}}(2 D)=r_{\mathrm{c}}(3 D) .
\end{aligned}
$$

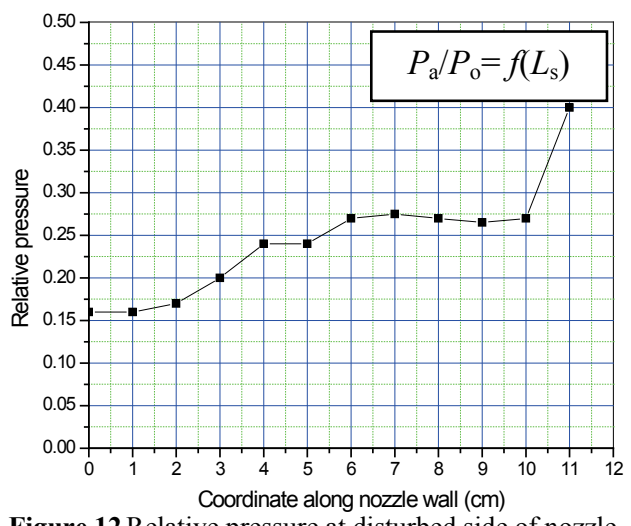

Figure 12 Relative pressure at disturbed side of nozzle, $A z=20 \%, \beta=70^{\circ}, \delta=0[6]$

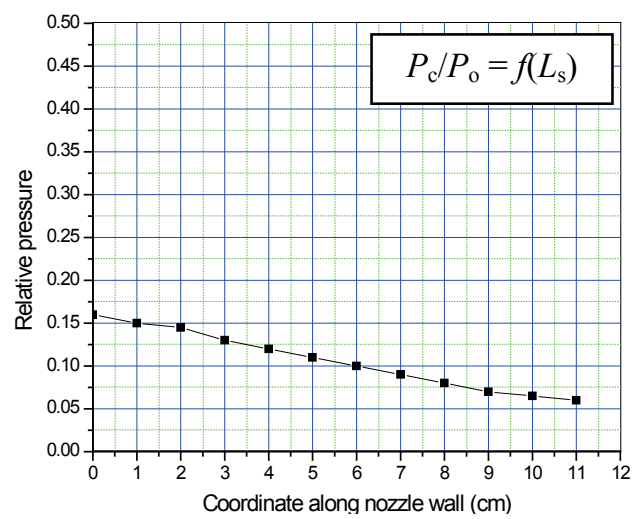

Figure 13 Relative pressure at non-disturbed side of nozzle, $A_{\mathrm{z}}=20 \%, \beta=70^{\circ}, \delta=0[6]$

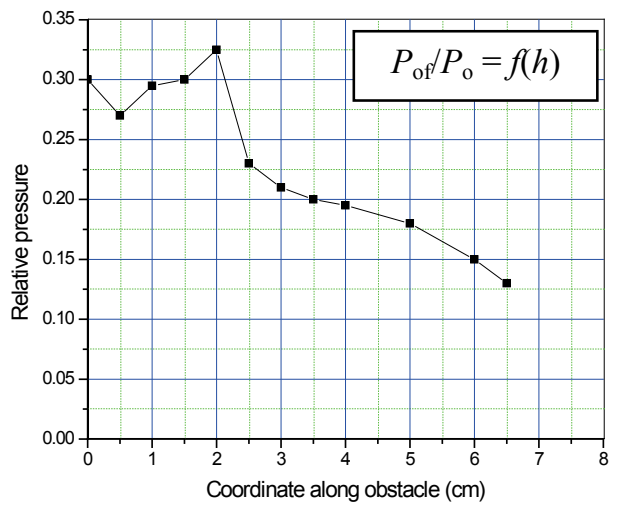

Figure 14 Relative pressure at front side of spoiler, $A_{\mathrm{z}}=20 \%, \beta=70^{\circ}, \delta=0[6]$

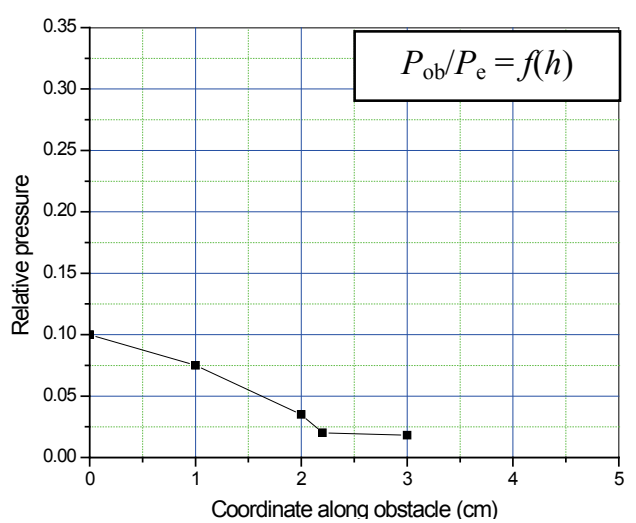

Figure 15 Relative pressure at back side of spoiler, $A_{\mathrm{z}}=20 \%, \beta=70^{\circ}, \delta=0[6]$

In the case of spoiler:

$A_{\mathrm{z}}(2 D)=0,011+1,6889 \cdot A_{\mathrm{z}}(3 D)-$

$-2,853 \cdot A_{\mathrm{z}}(3 D)^{2}+2,8913 \cdot A_{\mathrm{z}}(3 D)^{3}$,

$\delta(2 D)=\delta(3 D)$,

$\beta=\frac{\pi}{2}-\alpha_{\mathrm{d}}$.

In the case of dome deflector we have:

$$
\begin{aligned}
& A_{\mathrm{z}}(2 D)=A_{\mathrm{z}}(3 D), \\
& \delta(2 D)=\delta(3 D), \\
& \beta(2 D)=\beta_{\mathrm{av}}(3 D) .
\end{aligned}
$$




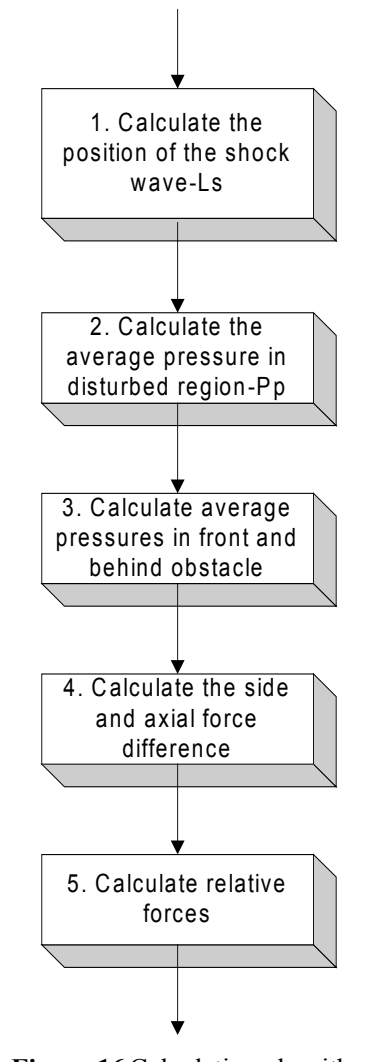

Figure 16 Calculation algorithm

The proposed methodology algorithm is:

1) Calculate position of shock wave $L_{\mathrm{s}}$ :

From the analyses, the following correlation was established:

$\frac{L_{\mathrm{s}}}{X_{\mathrm{e}}}=\left(1,385 \cdot A_{\mathrm{z}}^{0,65}-189,17 \cdot A_{\mathrm{z}}^{2} \cdot \mathrm{e}^{-40 \cdot A_{\mathrm{z}}}\right) \cdot f(\beta, \delta)$,

$f(\beta, \delta)=\left(1-0,47 \cdot(\beta-1,22)^{1,774} \cdot(1+\delta)^{9,85}\right)$,

for the nozzle angles $\alpha_{\mathrm{d}} \geq 20^{\circ}$, otherwise it was:

$\frac{L_{\mathrm{s}}}{X_{\mathrm{e}}}=\left[1,385 \cdot A_{\mathrm{Z}}^{0,65 \cdot \mathrm{e}^{-5 A_{\mathrm{Z}} \cdot\left(0,35-\alpha_{\mathrm{d}}\right)}-}\right.$

$\left.-189,17 \cdot A_{\mathrm{z}}^{2} \cdot \mathrm{e}^{-40 \cdot A_{\mathrm{z}}}\right] \cdot f(\beta, \delta)$.

2) Calculate average pressure in disturbed region " $\mathrm{C} " p_{\mathrm{p}}$ :

$\frac{p_{\mathrm{p}}}{p_{0}}=p_{1} \cdot\left(1+0,2 \cdot \frac{\kappa \cdot M_{1}^{2}}{\left(M_{1}^{2}-1\right)^{0,25}}\right) \cdot f(\delta) \cdot f(\beta)$.

- $f$ (nozzle type),

$f(\delta)=\frac{1}{1+\delta^{0,6}}$

$f(\beta)=\frac{1}{1+0,17 \cdot(\beta-1,22)^{2,5}}$,

adjustment for $2 D$ nozzle is

$f($ nozzle type $)=1-62,2 \cdot \mathrm{e}^{-2,3 \cdot M_{1}} \cdot \cos \left(0,93 \cdot M_{1}\right)$, while for $3 D f($ nozzle type $)=1$.

3) Calculate the average pressures before and after the obstacle:

Average pressure before the obstacle is calculated as:

$$
\frac{p_{\text {of }}}{p_{0}}=1,15 \cdot \psi \cdot f(\delta) \cdot f(\beta),
$$

where function $\psi$ depends on Mach number of parameter $z$, which is defined as:

$$
z\left(M_{1}\right)=\frac{\kappa \cdot M_{1}^{2}}{1+\frac{\kappa-1}{2} \cdot M_{1}^{2}}
$$

when $z \leq 4,5$ function $\psi$ is defined as:

$$
\begin{aligned}
& \psi=-1,66256+2,1424 \cdot z-0,6018 \cdot z^{2}+ \\
& +1,9446 \times 10^{-3} \cdot z^{3}+0,01721 \cdot z^{4}-1,56375 \times 10^{-3} \cdot z^{5}
\end{aligned}
$$

Otherwise it is defined as:

$\psi=2,6 \cdot\left(1+\frac{\kappa-1}{2} \cdot M_{1}^{2}\right)^{\frac{\kappa}{\kappa-1}}$

Adjustments for the gap and Beta angle are:

$$
\begin{aligned}
& f(\delta)=\left(1-\frac{\delta}{2}\right)^{2}, \\
& f(\beta)=-1,256+2,77 \cdot \beta-0,755 \cdot \beta^{2}
\end{aligned}
$$

Average pressure after the obstacle is calculated as

$$
\frac{p_{\mathrm{ob}}}{p_{\mathrm{e}}}=\left(1+\left(0,6+2,74 \cdot \delta^{0,5}\right) \cdot \mathrm{e}^{-50 \cdot A_{\mathrm{Z}}^{4}}\right) \cdot f(\beta),
$$

where Beta angle correction is

$$
f(\beta)=1+0,1844 \cdot \beta-0,151 \cdot \beta^{2}
$$

4) Calculate side and axial force difference:

Forces acting on divergent part of the nozzle, with an obstacle, are:

$$
\begin{aligned}
& F_{\mathrm{a} y}=D_{\mathrm{cr}} \cdot \int_{0}^{L_{\mathrm{S}}} p_{\mathrm{p}} \cdot \mathrm{d} x \cdot \cos \alpha_{\mathrm{d}}, \\
& F_{\mathrm{a} x}=D_{\mathrm{cr}} \cdot \int_{0}^{L_{\mathrm{S}}} p_{\mathrm{p}} \cdot \mathrm{d} x \cdot \sin \alpha_{\mathrm{d}} .
\end{aligned}
$$

Forces acting on divergent part of the nozzle, with no obstacles, are: 


$$
\begin{aligned}
& F_{\mathrm{c} y}=D_{\mathrm{cr}} \cdot \int_{0}^{L_{\mathrm{S}}} \frac{p_{1}+p_{\mathrm{e}}}{2} \cdot \mathrm{d} x \cdot \cos \alpha_{\mathrm{d}}, \\
& F_{\mathrm{c} x}=D_{\mathrm{cr}} \cdot \int_{0}^{L_{\mathrm{s}}} \frac{p_{1}+p_{\mathrm{e}}}{2} \cdot \mathrm{d} x \cdot \sin \alpha_{\mathrm{d}} .
\end{aligned}
$$

Forces acting on the front side of the obstacle are:

$$
\begin{aligned}
& F_{\text {of } y}=-D_{\text {cr }} \cdot \int_{0}^{h} p_{\text {of }} \cdot \mathrm{d} x \cdot \cos \left(\alpha_{\mathrm{d}}+\beta\right), \\
& F_{\text {of } x}=D_{\text {cr }} \cdot \int_{0}^{h} p_{\text {of }} \cdot \mathrm{d} x \cdot \sin \left(\alpha_{\mathrm{d}}+\beta\right) .
\end{aligned}
$$

Forces acting on the back side of the obstacle:

$$
\begin{aligned}
& F_{\mathrm{ob} y}=-D_{\mathrm{cr}} \cdot \int_{0}^{h} p_{\mathrm{ob}} \cdot \mathrm{d} x \cdot \cos \left(\alpha_{\mathrm{d}}+\beta\right), \\
& F_{\mathrm{ob} x}=D_{\mathrm{cr}} \cdot \int_{0}^{h} p_{\mathrm{ob}} \cdot \mathrm{d} x \cdot \sin \left(\alpha_{\mathrm{d}}+\beta\right) .
\end{aligned}
$$

Resultant forces are:

$$
\begin{aligned}
& F_{y}=\left[F_{\mathrm{a} y}-F_{\mathrm{c} y}\right]+\left[F_{\mathrm{of} y}-F_{\mathrm{ob} y}\right], \\
& F_{x}=\left[F_{\mathrm{a} x}-F_{\mathrm{c} x}\right]-\left[F_{\mathrm{of} x}-F_{\mathrm{ob} x}\right] .
\end{aligned}
$$

\section{5) Calculate relative forces:}

Relative forces are calculated according to the thrust in a non-disturbed nozzle. The well-known equations for the thrust are:

$$
\begin{aligned}
& F_{0}=C_{\mathrm{F}} \cdot p_{0} \cdot A_{\mathrm{cr}}, \\
& F_{y \mathrm{r}}=\frac{F_{y}}{F_{0}}, \\
& F_{x \mathrm{r}}=\frac{F_{x}}{F_{0}} .
\end{aligned}
$$

Thrust vector angle is calculated as:

$$
\theta=\arctan \left(\frac{F_{y \mathrm{r}}}{1-F_{x \mathrm{r}}}\right),
$$

and ratio of side to thrust loss force is calculated as:

$$
\kappa=\frac{F_{y \mathrm{r}}}{F_{x \mathrm{r}}} .
$$

\section{Pressure distribution in disturbed region consideration}

Tests show that after oblique shock wave pressure is increasing almost linear before boundary layer separation. The length of that zone is related to the boundary layer thickness and can be approximated between $2,1 \div 2,7$ times boundary layer thickness for Mach numbers from 1,6 to 6 . After that pressure is almost constant $\left(p_{\mathrm{p}}\right.$ - plato zone) and is increasing to the value $p_{\text {of }}$ immediately before the obstacle. The length of plato zone also can be roughly estimated as $4,2 \div 4,7$ times obstacle length.

Investigations which were done are usually related to the flow where one side is without surrounding wall i.e. flat plate and obstacle. Typical relations are presented below:

$p_{\mathrm{p}}=p_{1} \cdot\left(1+0,5 \cdot M_{1}\right)$

according to $[8]$

$p_{\mathrm{p}}=p_{1} \cdot\left(1+0,2 \cdot \frac{\kappa \cdot M_{1}^{2}}{\left(M_{1}^{2}-1\right)^{0,25}}\right)$,

according to $[2]$

$p_{\mathrm{p}}=p_{1} \cdot\left(0,515+0,675 \cdot M_{1}\right)$,

according to [9].

Obviously, they are related to the conditions at point 1 which is directly related to the obstacle. In our investigations we analysed the effects of the geometry of obstacle in $2 D$ and $3 D$ nozzles. Summary of these investigations is in Eqs. (6) and (7). Comparison between previous investigations and our results is presented in the figure below.

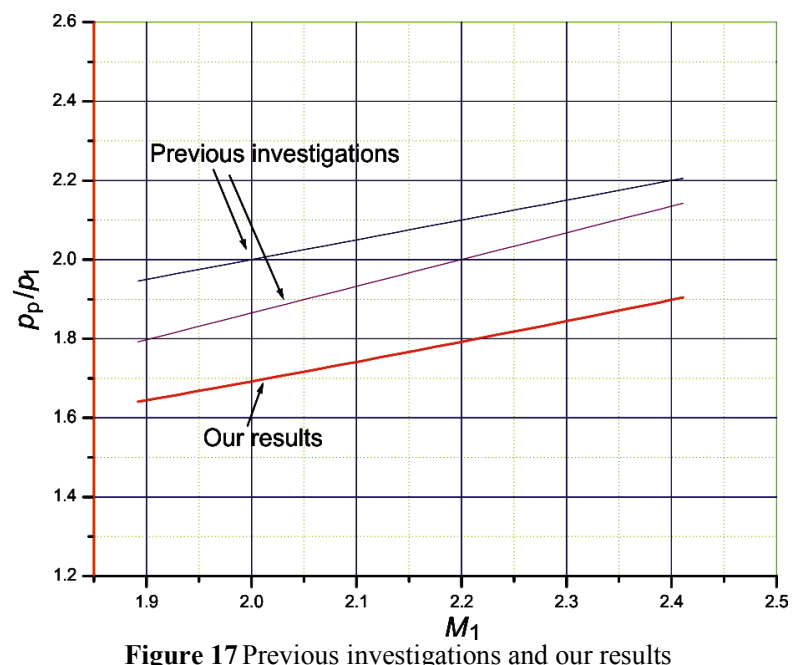

It is also interesting to note that pressure distribution in the nozzle with obstacle at exit is similar to the separation but without obstacle. Analogy is evident: in flow without obstacle separation will occur in too much over-expanded nozzle when atmospheric pressure is practically acting as obstacle. Most known criteria for such separation are from Summerfield [7] estimating flow separation when expanded exit pressure is $40 \%$ of atmospheric. 


\section{Mathematical model comments and comparison with test results}

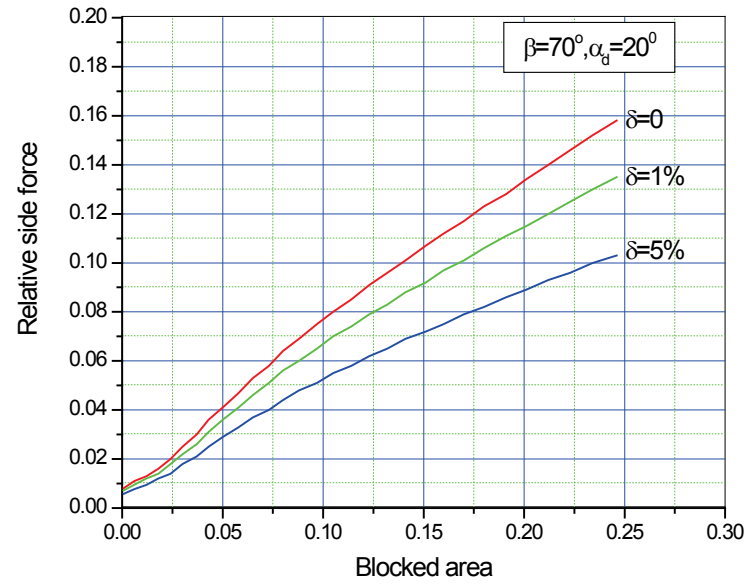

Figure 18 Relative side force vs. blocked area for different delta angle

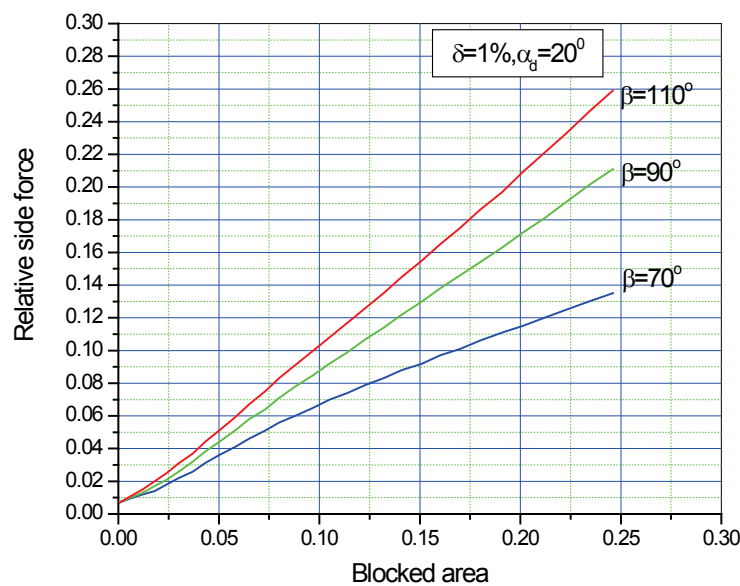

Figure 19 Relative side force vs. blocked area for different beta angle

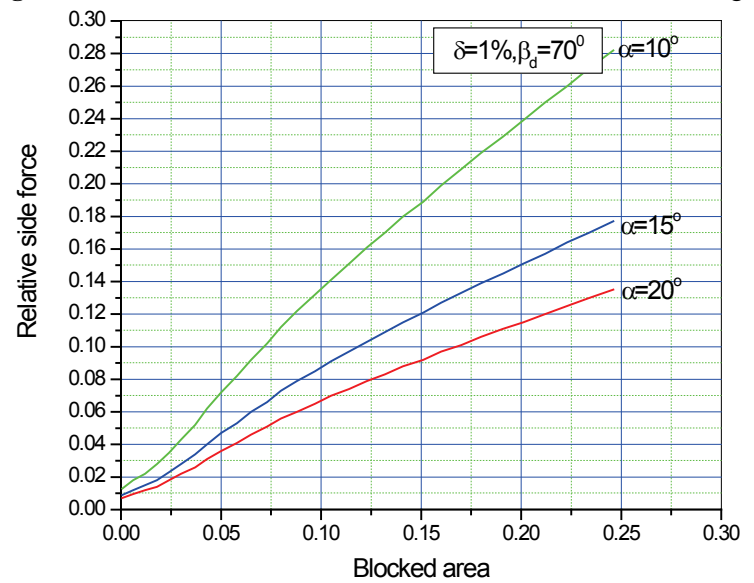

Figure 20 Relative side force vs. blocked area for different alpha angle

Results from mathematical model are being presented in Figs. $18 \div 23$. They contribute to the general discussion on geometrical effect on TVC system. The following can be concluded:

- For all the graphs, values below $5 \%$ of blocked area are not confirmed because tests were not performed with such small values. Also, in that area, boundary layer is of the order of the blockage which can have very strong influence.
- $\quad$ Side and thrust vector loss force are increasing almost linearly with blockage area in engineering used values from 5 to $20 \%$.

- With increasing Beta angle from $70^{\circ}$ (normal to flow) side force and thrust vector angle are increasing (jet tab to dome deflector). Thrust loss is also increasing but ratio of forces is better with increasing Beta angle after $10 \%$ of blockage.

- With increasing the gap between obstacle and nozzle efficiency of the system is generally decreasing.

- Smaller values of nozzle divergent angle are increasing the system efficiency but it is usually not design parameter for the TVC system.

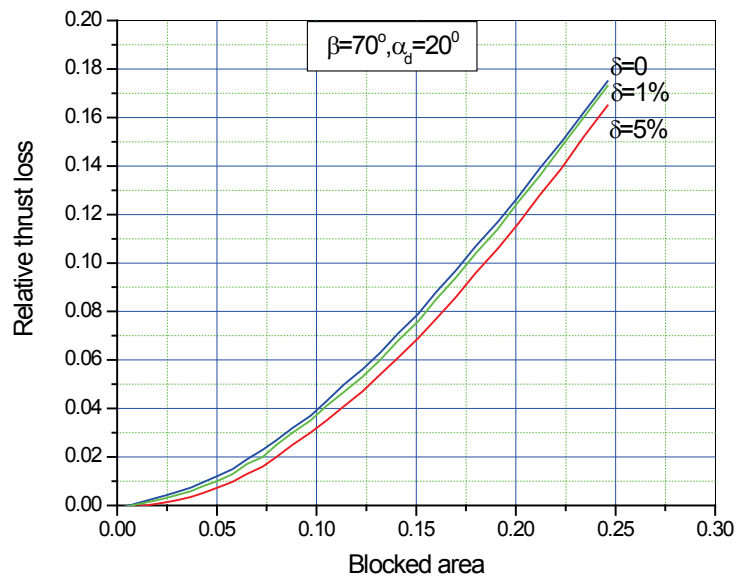

Figure 21 Relative thrust loss vs. blocked area for different delta angle

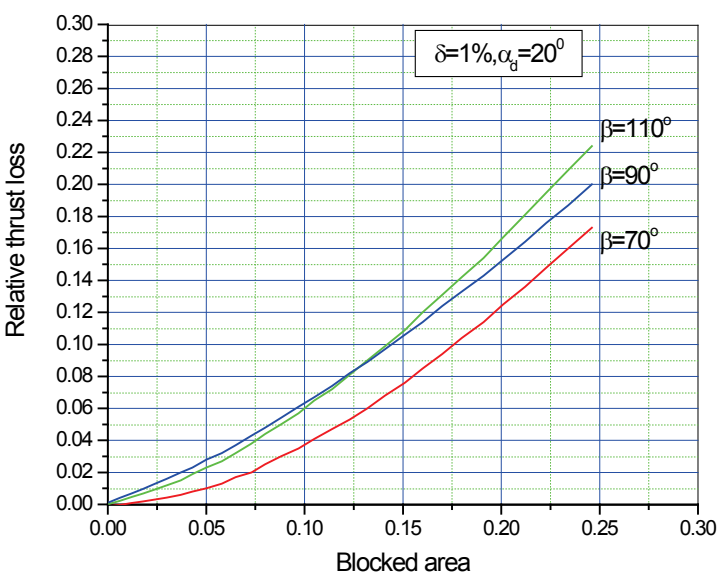

Figure 22 Relative thrust loss vs. blocked area for different beta angle

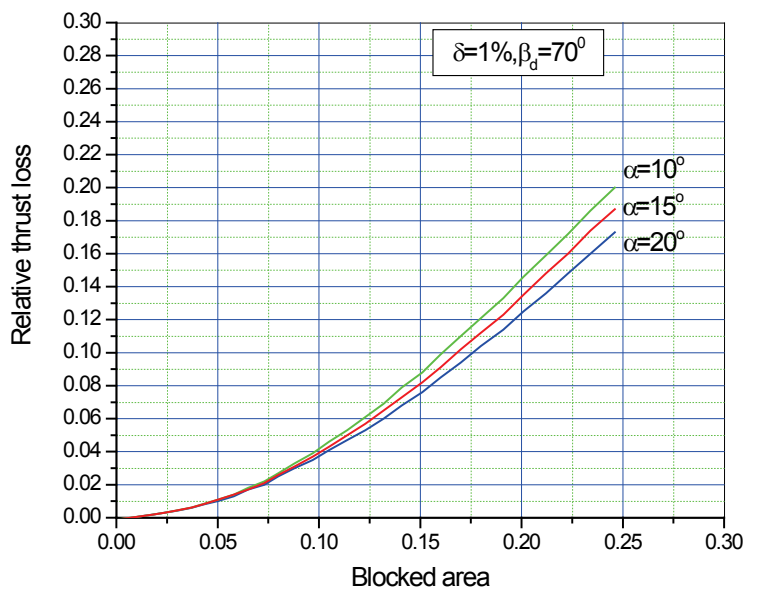

Figure 23 Relative thrust loss vs. blocked area for different alpha angles 
Comparison with test data (Fig. 25) shows excellent result for side force, while for the thrust loss; the model is acceptable up to the relative blockage of $20 \%$, what is also being practical area of using TVC. It is very difficult to predict pressure after the obstacle for greater values of blockage, which causes differences between the model and test. Tests were performed with real rocket motor and six components test stand at EDePro company site (www.edepro.com), Fig. 24.

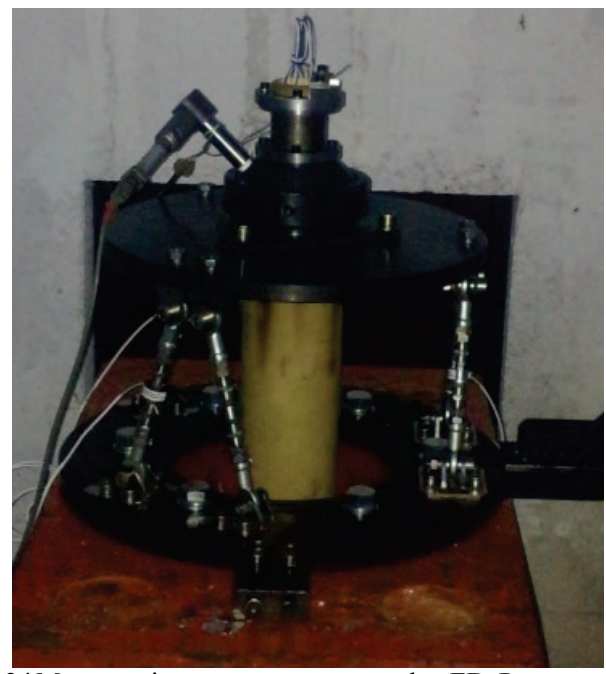

Figure 24 Motor at six-component test stand at EDePro company site

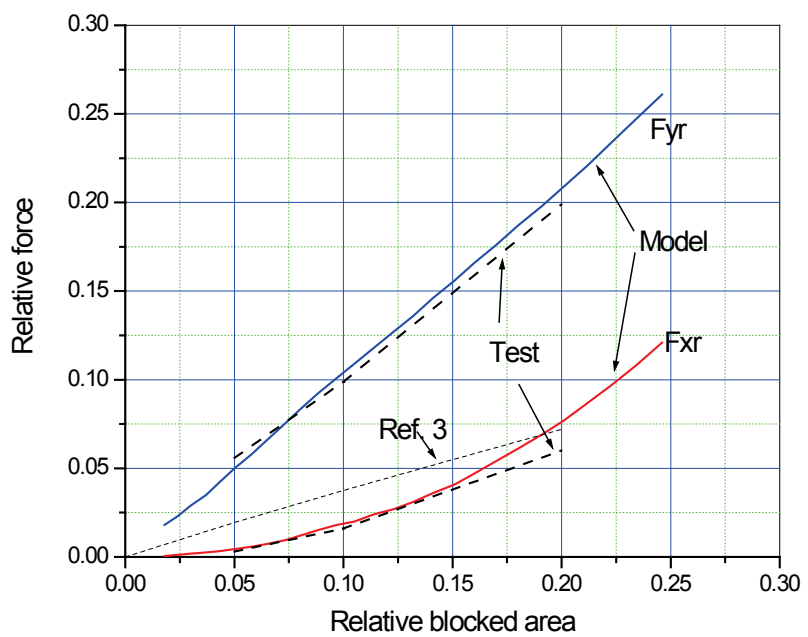

Figure 25 Mathematical model, test and ref. 3 comparison

Table 1 Mathematical model and test comparison

\begin{tabular}{|c|c|c|c|c|}
\hline & \multicolumn{2}{|c|}{ Model } & \multicolumn{2}{c|}{ Test } \\
\hline$A_{\mathrm{z}}(\%)$ & $F_{\mathrm{yr}}(\%)$ & $F_{x \mathrm{r}}(\%)$ & $F_{\mathrm{yr}}(\%)$ & $F_{x \mathrm{r}}(\%)$ \\
\hline 5 & 4,9 & 0,4 & 5,6 & 0,3 \\
\hline 10 & 10,4 & 1,9 & 9,9 & 1,6 \\
\hline 20 & 20,7 & 7,5 & 19,9 & 6,0 \\
\hline
\end{tabular}

\section{Conclusions}

Developed mathematical model is applicable in both spoiler and dome deflector TVC because all experimental data are transformed to the equivalent $2 \mathrm{D}$ nozzle. Its accuracy, when compared against the experimental results, is excellent in the area between 5 and $20 \%$ of the blockage. Side force shows complete linear behaviour, which is preferable for control. The model uses engineering design parameters such as $\alpha_{\mathrm{d}}$ and $\beta$, and also control parameter $A_{\mathrm{z}}$ which gives this method an engineering character and practical usage. Also, model is derived from test data from both wind tunnel and rocket motor testing which proves the model applicability.

\section{Notice}

Short version of this paper has been presented and published in "Proceedings of $2^{\text {nd }}$ International Conference on Manufacturing Engineering \& Management 2012" [12].

\section{Acknowledgement}

Research of this paper is the result of the national project financed by the Serbian Ministry of Education and Science (TR 35044).

\section{References}

[1] Jojić, B.; Blagojević, Đ.; Fotev, V.; Miloš, M. et al. Rocket propulsion research-thrust vector control, Jet Propulsion Laboratory Faculty of Mechanical Engineering University of Belgrade, 1984-1986.

[2] Abramovič, G. N. Прикладная газовая динамика, Наука, Moscow, 1976

[3] Eatough, R. G. Improved jet tab thrust vector control for the BGM-34C booster, AFRPL TR-77-49, 1977.

[4] Jojić, B.; Milinović, M.; Stefanović, Z.; Blagojević, Đ. Pressure distribution in rocket nozzle with mechanical system for TVC, AIAA Propulsion Conference, San Diego, 1987.

[5] Stefanović, Z. Research of fluid flow and pressure distribution in supersonic nozzle in connection with vector thrust control, $\mathrm{PhD}$ thesis, Faculty of Mechanical Engineering University of Belgrade, 1986.

[6] Jojić, B. et al. Research from modern rocket propulsionTVC-physical model, Jet Propulsion Laboratory Faculty of Mechanical Engineering University of Belgrade, 1986.

[7] Almqvist, Marcus. Semi-empirical model for supersonic flow separation in rocket nozzles, Master thesis, Lulea University of Technology, Kiruna 2005.

[8] Zukoski, E. E. Turbulent boundary layer separation in front of forward facing step. // AIAA Journal. 5, 10(1967). DOI: $10.2514 / 3.4299$

[9] Gogis, L. V.; Stepanov, G. J. Турбулентние отривние течения, Nauka, Moskva, 1979.

[10] Chang, P. K. Control of the flow separation, Hemisphere, Washington, 1977.

[11] Krasnov, N. F. Метод аеродинамическог рашцота, Moskva, Machinostroenie, 1984.

[12] Davidović, N.; Miloš, P.; Jojić, B.; Blagojević, Dj.; Miloš, M. Jet Tab and Dome Deflector TVC in Solid Rocket Motor Mathematical Model and Test Comparison. // Proceedings of $2^{\text {nd }}$ International Conference on Manufacturing Engineering \& Management 2012, Presov, Slovak Republic, December 5-7, 2012, pp. 59-63.

[13] Nauparac, D. B.; Pršić, D. H.; Miloš, M. V.; Todić, I. S. Different modeling technologies of hydraulic load simulator for thrust vector control actuator. // Tehnički vjesnik-Technical Gazette. 22, 3(2015), pp. 599-606. DOI: 10.17559/TV-20140621063240

\section{Nomenclature}

$A$ Area $\left(\mathrm{m}^{2}\right)$

$C_{\mathrm{f}}$ thrust coefficient 
$F$ force (N)

$F_{0}$ thrust without TVC (N)

$h$ obstacle height (m)

$\kappa$ ratio of thrust side to loss force

$L_{\mathrm{s}}$ position of shock wave measured from exit (m)

$M$ Mach number

$p$ pressure $(\mathrm{Pa})$

$p_{0}$ total pressure before shock wave $(\mathrm{Pa})$

$r_{\mathrm{c}}$ nozzle radius $(\mathrm{m})$

$X_{\mathrm{e}}$ nozzle wall length from throat to exit (m)

$\alpha_{\mathrm{d}}$ nozzle divergence angle ( $\left.\mathrm{rad}\right)$

$\beta$ obstacle nozzle angle (rad)

$\theta$ thrust vector angle (rad)

$\delta$ obstacle relative gap

\section{Subscripts}

1 parameters just before the shock wave

a area in disturbed region in nozzle, axial

b blocked

c area in non-disturbed region in nozzle

cr critical

e exit

of obstacle front

ob obstacle back

$\mathrm{p}$ plato area (zone)

$r$ relative

$x$ axial direction

$y \quad$ lateral direction

$z$ relative blocked

\section{Authors' addresses}

\section{Nikola Davidović, PhD}

EDePro Company

Kralja Milutina 33, 11000 Belgrade, Serbia

E-mail: nikola.davidovic@edepro.com

\section{Predrag Miloš, PhD}

EDePro Company

Kralja Milutina 33, 11000 Belgrade, Serbia

E-mail: predrag.milos@edepro.com

\section{Branislav Jojić, full time professor}

Faculty of Mechanical Engineering University of Belgrade Kraljice Marije16, 11000 Belgrade, Serbia

E-mail: branislav.jojic@edepro.com

\section{Marko Miloš, associate professor}

Faculty of Mechanical Engineering University of Belgrade Kraljice Marije 16, 11000 Belgrade, Serbia

E-mail: mmilos@mas.bg.ac.rs 